A Preliminary Look at the Crust and Upper Mantle of North Africa Using Libyan Seismic Data

M.E. Pasyanos

August 8, 2005 
This document was prepared as an account of work sponsored by an agency of the United States Government. Neither the United States Government nor the University of California nor any of their employees, makes any warranty, express or implied, or assumes any legal liability or responsibility for the accuracy, completeness, or usefulness of any information, apparatus, product, or process disclosed, or represents that its use would not infringe privately owned rights. Reference herein to any specific commercial product, process, or service by trade name, trademark, manufacturer, or otherwise, does not necessarily constitute or imply its endorsement, recommendation, or favoring by the United States Government or the University of California. The views and opinions of authors expressed herein do not necessarily state or reflect those of the United States Government or the University of California, and shall not be used for advertising or product endorsement purposes.

This work was performed under the auspices of the U.S. Department of Energy by University of California, Lawrence Livermore National Laboratory under Contract W-7405-Eng-48. 


\section{A Preliminary Look at the Crust and Upper Mantle of North Africa Using Libyan Seismic Data}

Michael Pasyanos

Lawrence Livermore National Laboratory

In recent years, LLNL has been developing methods to jointly invert both surface wave dispersion data and teleseismic receiver functions. The technique holds great promise in accurately estimating seismic structure, including important tectonic parameters such as basin thickness, crustal thickness, upper mantle velocity, etc. We proposed applying this method to some recently available data from several Libyan stations, as we believe the technique has not been applied to any stations in Libya. The technique holds the promise of improving our understanding of the crust and upper mantle in Libya and North Africa.

We recently requested seismic data from stations GHAR (Gharyan) and MARJ (Al Marj) in Libya for about 20 events. The events were large events at regional distances suitable for making dispersion measurements. An example of waveforms recorded at the two stations from an earthquake in Italy is shown in Figure 1. The paths traverse the Ionian Sea. Notice the slow short period group velocities of the surface waves across the Mediterranean, particularly to the easternmost station MARJ.

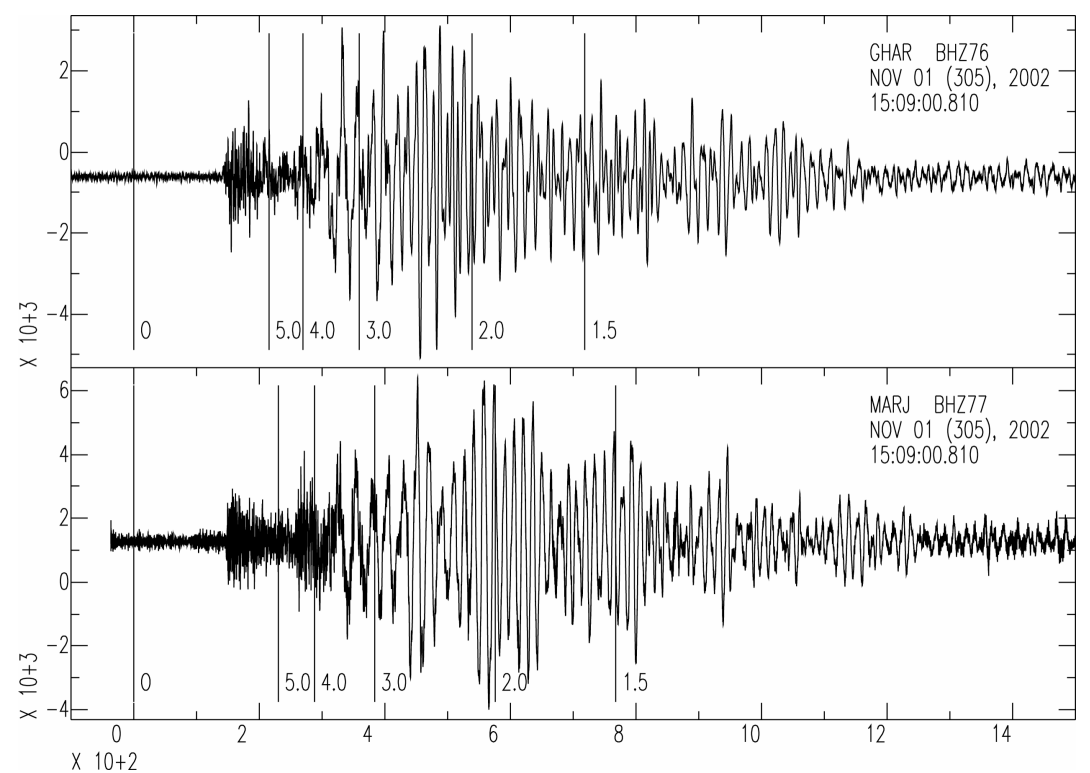

Figure 1. Waveforms from an earthquake in Italy recorded at Libyan stations GHAR and MARJ.

However, because of data availability, signal-to-noise ratio, etc. we were unable to make measurements for every one of these events at both stations. Figure 2 shows a map of paths for $20 \mathrm{sec}$ Rayleigh waves in the eastern Mediterranean region. Paths measured at the two Libyan stations are shown in green. 


\section{Eastern Mediterranean and vicinity}

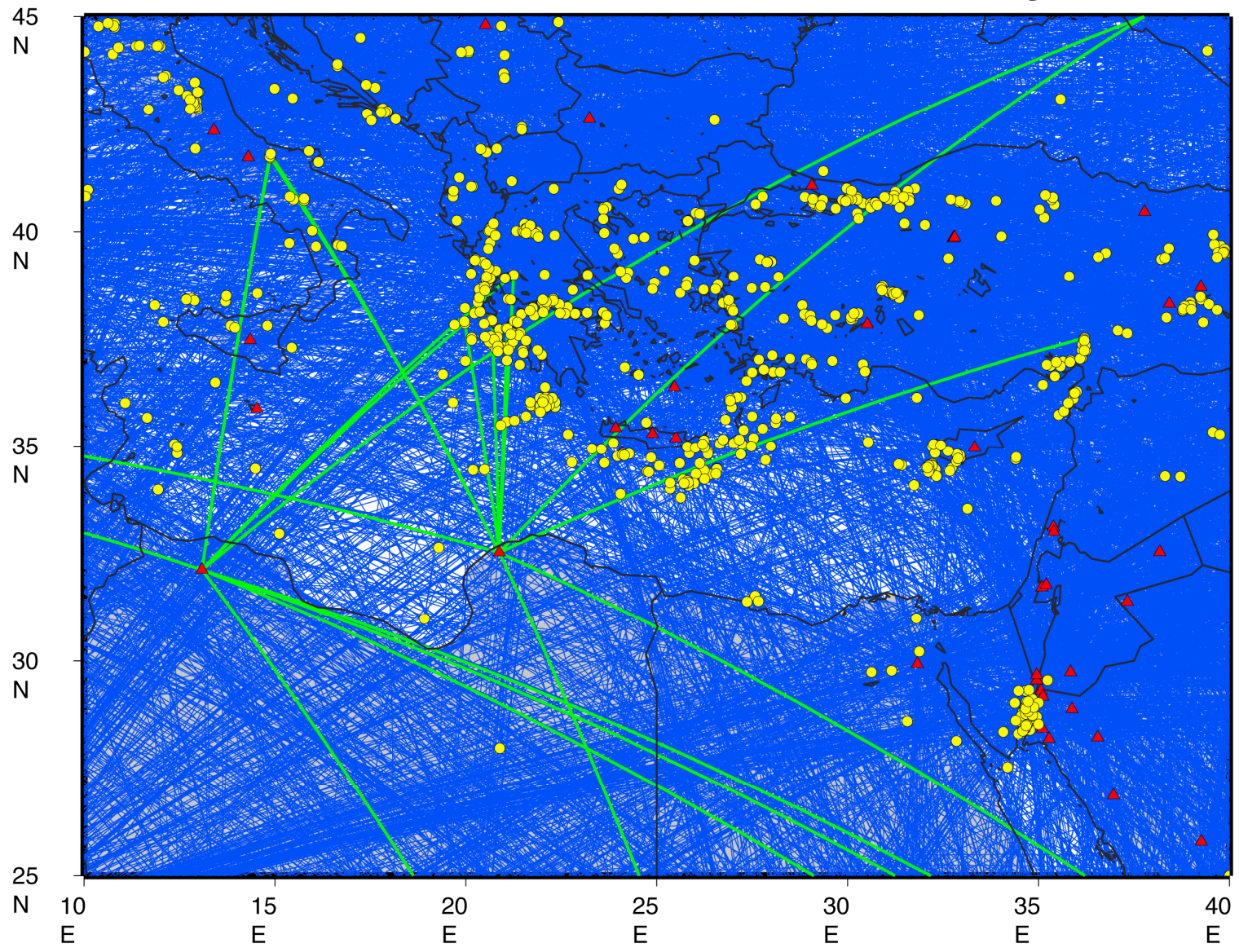

Figure 2. Surface wave dispersion paths for $20 \mathrm{sec}$ Rayleigh waves in the eastern Mediterranean. Paths to the Libyan stations are shown in green.

Rayleigh wave dispersion measurements at $20 \mathrm{sec}$ period are sensitive to velocities in the upper $20 \mathrm{~km}$ or so, and reveal sediment thickness, crustal velocity, and crustal thickness. Tomographic inversions reveal the sharp group velocity contrast between regions with deep sedimentary basins and those without. Figure 3, the result of an inversion made before adding the new dispersion measurements, shows slow group velocities in the Black Sea, Adriatic Sea, and Eastern Mediterranean. In general, these features correspond well with the sediment thickness model from Laske, shown in Figure 4. Details in and around the Sirt (Sirte) Basin in northern Libya, however, are poorly defined. 


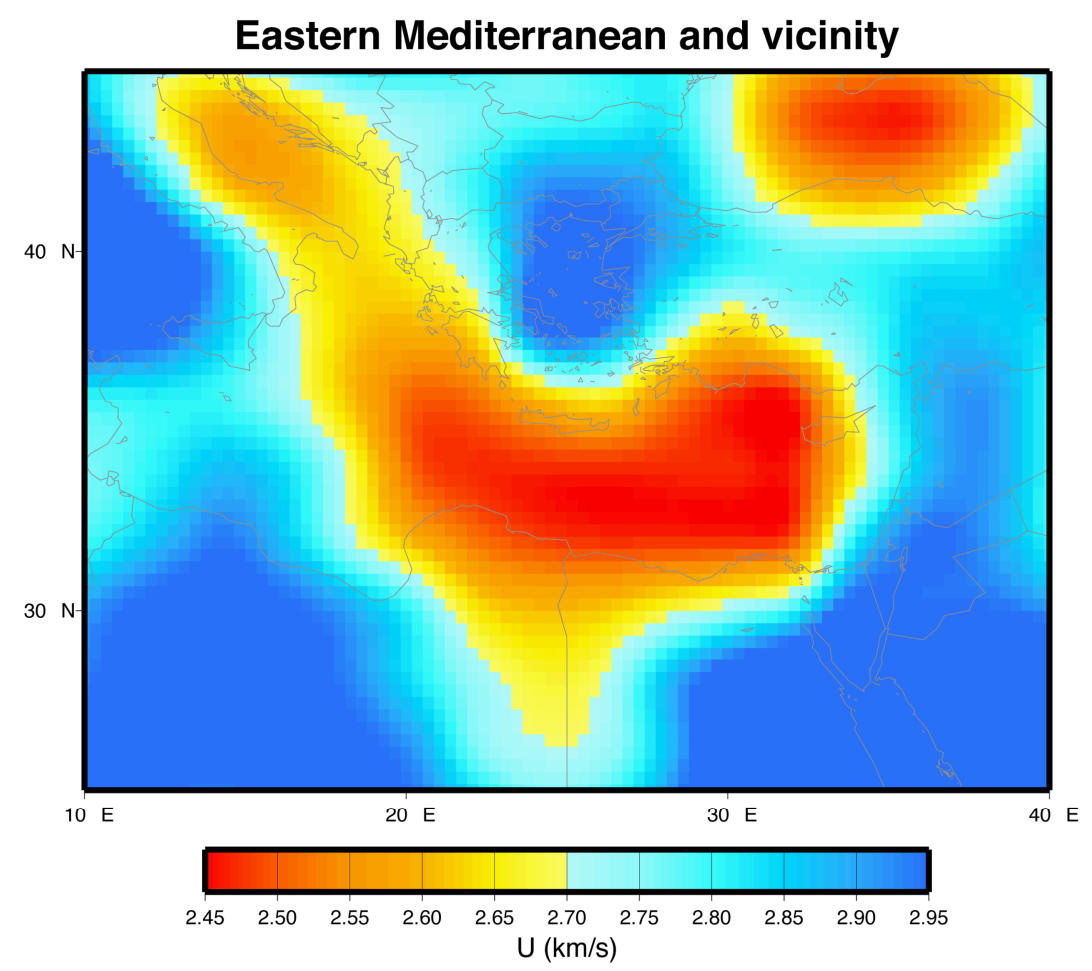

Figure 3. Group velocity of $20 \mathrm{sec}$ Rayleigh waves in the eastern Mediterranean. This inversion was made before the addition of Libyan paths.

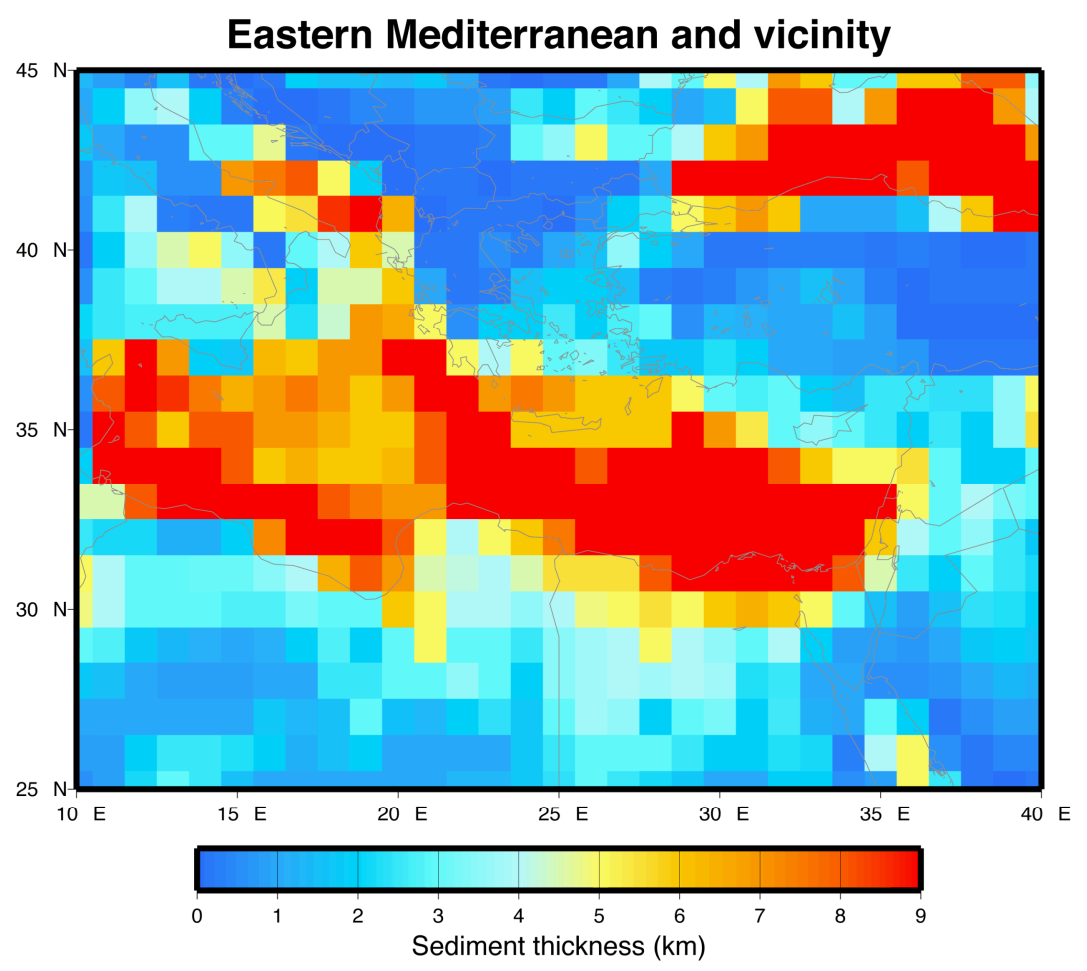

Figure 4. Sediment thickness map of the eastern Mediterranean from Laske sediment model. 


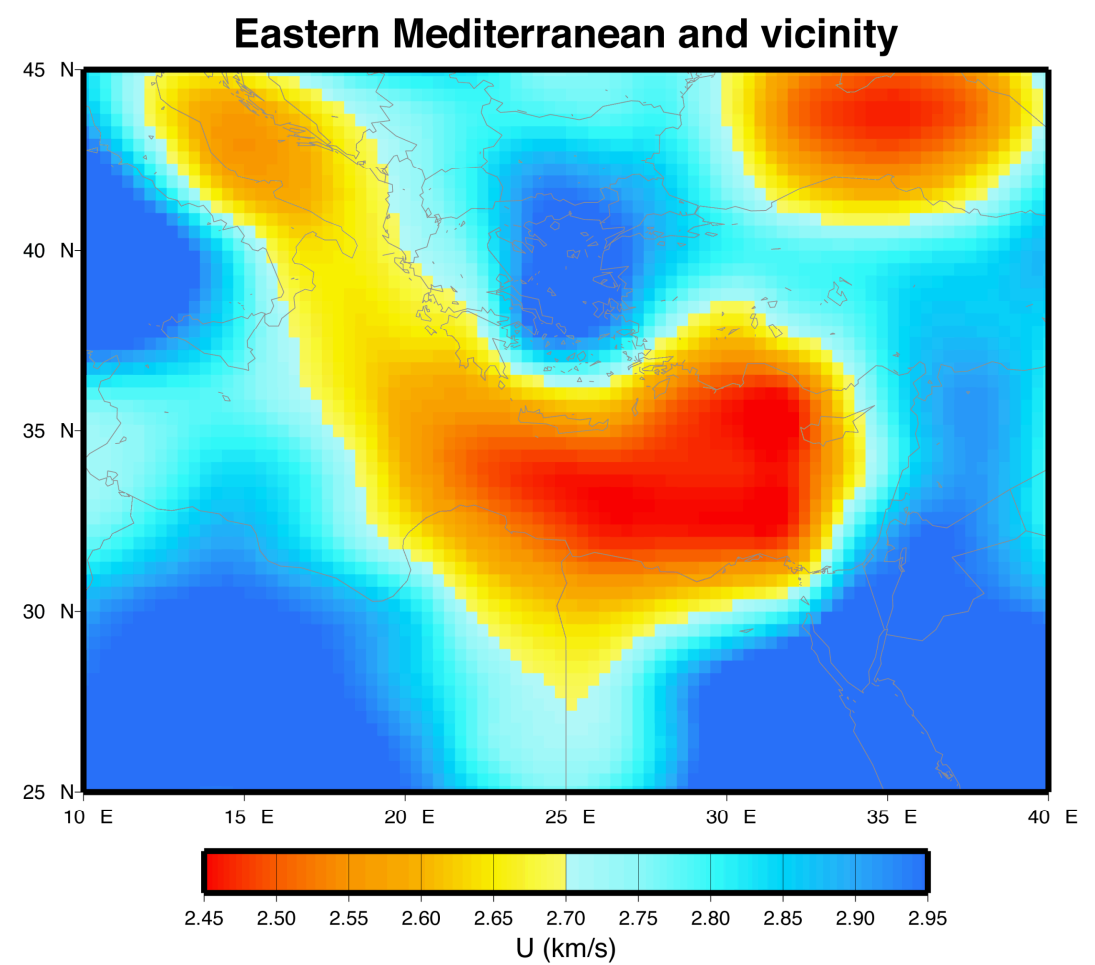

Figure 5. Group velocity of $20 \mathrm{sec}$ Rayleigh waves in the eastern Mediterranean.

This inversion was made after the addition of Libyan paths.

We have rerun the tomographic inversion after adding in the dispersion measurements made at the Libyan stations. The results are shown in Figure 5. For the most part, the maps are very similar. There is, however, a difference in the extent of the eastern Mediterranean Basin along the Libyan-Egyptian border. The extent of the basin more closely matches the boundaries of the sedimentary basins outlined in Figure 4. We expect that, with more data from nearby stations, we could further improve these maps and, in particular, start to see the Sirt Basin emerge as a feature. With coverage from events coming to the south, we would expect to see similar improvement for the Murzuk and Kufra basins in south Libya. The maps for Love and Rayleigh waves at periods ranging from 7 to $100 \mathrm{sec}$ could then be inverted for crust and upper mantle structure as performed in Pasyanos and Walter (2002).

At this point, we do not have any teleseismic events from which to perform receiver functions. By determining these at stations GHAR and MARJ and combining the receiver functions with the surface wave measurements, we can significantly improve our understanding of the crust and upper mantle in Libya and North Africa. 